\title{
Considerações sobre o Problema da Verdade em Espinosa
}

\section{Marcos André Gleizer*}

Resumo: Este artigo examina alguns aspectos do pensamento de Espinosa que tornam possível o estabelecimento de uma relação de complementaridade entre as noçōes de adequação e correspondência em sua concepção da verdade, procurando opor esta relação àquela existente entre as noções de evidência e verdade na concepção cartesiana.

Palavras-chave: definição de verdade - critério de verdade - correspondência - adequação-coerência

Gostaria de apresentar algumas breves considerações sobre o problema da verdade em Espinosa. Entretanto, é necessário precisar inicialmente que sob a rubrica "problema da verdade", encontra-se na realidade contido um conjunto de questões distintas, ainda que essencialmente ligadas entre si. Por "problema da verdade" devemos compreender antes de mais nada o problema que concerne à determinação da natureza ou essência da verdade. Trata-se de responder à questão sobre o significado do termo "verdade". Em seguida, podem-se formular as perguntas que recaem sobre as condições de possibilidade da verdade, isto é, pode-se buscar responder às seguintes questões: $1^{2}$ ) sendo dada a definição da verdade, que condições gerais devem ser satisfeitas para que existam idéias verdadeiras? $2^{\circ}$ ) que condições devem ser satisfeitas para que nós (mentes finitas) tenhamos idéias verda-

* Professor do Departamento de Filosofia da Universidade Federal do Rio de Janeiro. 
deiras? $\left.3^{2}\right)$ que condições devem ser satisfeitas para que nós saibamos que temos idéias verdadeiras, isto é, para que possamos reconhecer e discriminar as idéias verdadeiras das falsas? Trata-se do problema do critério da verdade.

A conexão entre a primeira e a última dessas questões não é desprovida de uma certa tensão interna. Alguns autores consideram que a investigação sobre a definição da verdade é completamente independente daquela sobre o critério da verdade. Outros sustentam que toda investigação sobre o conceito de verdade permaneceria vazia se ela não fosse capaz de nos mostrar como podemos reconhecer a verdade de um juízo dado. Para estes, a resposta à primeira questão depende de uma tomada em consideração da exigência expressa pela última. Espinosa se situa, no meu entender, nesta segunda perspectiva.

Mas que a questão sobre a determinação da natureza da verdade possa ser considerada como um "problema", eis algo de problemático ou de paradoxal em si. Efetivamente, se nós não soubéssemos de antemão o que é a verdade, como poderíamos aprendê-lo? Que razões teríamos para aceitar uma determinada definição dentre as múltiplas definições possíveis? Como encontrar a verdadeira definição da verdade? Este problema foi colocado por Descartes numa carta a Mersenne (16 de outubro de 1639), onde ele afirma que a noção de verdade como conformidade do pensamento ao objeto é "tão transcendentalmente clara, que é impossível ignorá-la". Sua solução para o problema colocado acima consiste em afirmar que nós possuímos um "conhecimento natural" da noção de verdade. Para ele, portanto, o "problema da verdade" restringe-se à possibilidade de encontrar e fundar o critério de verdade, onde o sentido do termo "verdade" é cristalino e naturalmente dado ao espírito.

Pode-se evidentemente concordar com Descartes que se nós não possuíssemos uma compreensão natural do sentido da verdade, à qual nós podemos e devemos fazer apelo para nos guiar na investigação, nós permaneceríamos no vazio e no arbitrário. Apenas, isto não implica que este "conhecimento natural" seja tão transcendentalmente claro quanto parece sê-lo para Descartes, nem tampouco que ele esgote o conteúdo do conceito de verdade. Pode-se muito bem sustentar que o que nós conhecemos natural- 
Gleizer, M.A., discurso (24), 1994: 129-145

mente da verdade e que nós explicamos quid nominis, isto é, a definição nominal da verdade, recai apenas sobre a propriedade ou denominação extrínseca da idéia verdadeira, e que esta definição, correspondendo a um nível ainda superficial da reflexão sobre a idéia verdadeira, fornece simplesmente o ponto de partida para uma investigação mais aprofundada sobre a natureza da verdade.

Tudo se passa como se esta definição fornecesse um instrumento natural primeiro, parcial e incompleto, com a ajuda do qual a alma, por um movimento reflexivo, pudesse progredir no sentido de um aprofundamento da compreensão da forma da idéia verdadeira.

Ora, este esforço reflexivo, este questionamento que atinge o conceito mesmo de verdade, seja para precisar a que ele se aplica, seja para explicitar uma outra determinação que não aquela fornecida pela definição nominal, parece-me concordar com a démarche efetiva do pensamento de Espinosa. Ao longo de toda sua obra, do Breve Tratado à Ética, ele examina criticamente a concepção da verdade como correspondência, buscando não apenas explicitar suas condições de possibilidade, mas sobretudo complementá-la com uma propriedade intrínseca que permita, por um lado, explicar que nós possamos saber com certeza que temos idéias verdadeiras e, por outro lado, que forneça à perspectiva ética um princípio explicativo da superioridade interna do sábio sobre o ignorante.

A mera correspondência do pensamento com o seu objeto não é capaz de fornecer uma resposta satisfatória às três questões que orientam a investigação espinosana sobre a verdade, e que são formuladas da seguinte maneira tanto no início (Breve Tratado, cap. XV, segunda parte ) quanto no término desta investigação (Espinosa 3, escólio da Proposição XLIII do Livro II):

Se a verdade consiste exclusivamente no acordo da idéia com o seu objeto, então ela distingue-se da falsidade apenas por uma denominação extrínseca. Mas então o homem que tem idéias verdadeiras não supera em nada o que tem apenas idéias falsas? Qual a causa das idéias falsas? E como podemos ter certeza de que temos idéias que concordam com seus objetos?

A resposta a essas questões repousa sobre a introdução da denominação intrínseca da idéia verdadeira, isto é, sobre a noção de adaequatio. É esta noção que permite explicar a automanifestação da verdade, excluindo a 
necessidade de uma marca ou signo extrínseco que permita reconhecê-la, é ela que funda a identificação espinosana entre idéia verdadeira e certeza, e é nela que consiste este "algo de real" pelo qual a idéia verdadeira se distingue da falsa. A investigação espinosana nos coloca assim diante de dois aspectos da idéia verdadeira. Todo o problema consiste em saber se entre estes dois aspectos há tensão, contradição ou complementaridade harmoniosa. Há em Espinosa duas teorias da verdade que se opõem numa relação conflituosa, que se justapõem numa coexistência pacífica ou dois aspectos que se completam numa concepção consistente da verdade? A resposta a esta questão divide os intérpretes do espinosismo.

Alguns, como o professor Raul Landim Filho, sustentam que há na Ética uma coexistência harmoniosa entre uma concepção da verdade como correspondência e uma concepção da verdade como coerência, ligada à noção de adequação:

"Estas questões colocadas pela definição da verdade encontram na Ética de Espinosa uma resposta tão sutil quanto original. Na Ética as duas teorias da verdade coexistem. Se a verdade é em primeiro lugar correspondência, é por um tipo de coerência que a verdade se impõe ao homem como correspondência" (Landim 5, p. 123)(1).

Outros, como Ferdinand Alquié, insistiram sobre o caráter conflituoso dessa coexistência. Ele fala de uma "certa tensão inerente ao conceito espinosista da verdade", tensão que reenvia a dificuldade de conciliar as três afirmações essenciais seguintes:

“1) a verdade é interior ao pensamento e se define não por sua relação com a coisa, mas por uma denominação intrínseca; 2) a verdade é sua própria marca, seu próprio signo, e aquele que possui uma idéia verdadeira não pode duvidar de sua verdade; 3) a verdade, malgrado as duas características precedentes, é acorćo da idéia e da coisa" (Alquié 1, p. 212). 
Outros ainda, diante desta tensão e desesperando de resolvê-la, escolheram suprimi-la privilegiando exclusivamente, entre os textos de Espinosa, seja aquelas passagens que vão no sentido das duas primeiras afirmações (são aqueles, como Hampshire ou Joachim, que consideram que Espinosa defende exclusivamente a concepção da verdade como coerência), seja aquelas passagens que vão no sentido da última afirmação (são aqueles, como Curley e Bennett, para quem Espinosa adota exclusivamente a concepção da verdade como correspondência).

É evidente que o procedimento que consiste em suprimir a tensão pela eliminação de um dos seus termos não é legítimo aqui. Ele seria legítimo se se pudesse mostrar que essas afirmações reenviam a momentos diferentes do pensamento do autor, isto é, se se pudesse dissolver a tensão na consideração da evolução temporal do pensamento de Espinosa. Mas tal não é o caso, já que nós a encontramos no interior de uma mesma obra (quer se trate da Ética ou do Tratado da Reforma do Entendimento $)^{(2)}$. Assim, ou bem é possível resolvê-la conceitualmente, ou bem é necessário reconhecer que ela reenvia a uma concepção inconsistente da verdade.

No meu entender, é a primeira dessas duas opções que é a correta. Não me parece que haja necessariamente mútua exclusão entre a teoria da verdade como coerência e aquela da verdade como correspondência, mas antes uma relação de complementaridade. A originalidade de Espinosa consiste precisamente em fazer da adaequatio e da convenientia dois aspectos complementares do conceito de verdade, aspectos estes que repousam sobre os dois aspectos da idéia espinosana, a saber: aspecto representativo, pelo qual a idéia reenvia ao seu objeto, e aspecto lógico-expressivo, pelo qual ela reenvia a outras idéias com as quais mantém necessariamente relações causaldedutivas (ver o $\$ 41$ do Tratado da Reforma do Entendimento). Sobre o primeiro repousa a correspondência e sobre o segundo a adequação.

Esta complementaridade é claramente afirmada por Espinosa na Carta LX a Tchirnhaus, mas é na Ética que ela é objeto de demonstração. Não pretendo entretanto analisar o mecanismo demonstrativo que exibe a possibilidade, e mesmo a necessidade, da conexão entre a adequação e a correspondência. Meu objetivo aqui será apenas examinar brevemente alguns aspectos do pensamento de Espinosa que, eliminando a tensão assinalada 
por Alquié, tornam possível esta complementaridade e iluminam a originalidade de sua concepção da verdade.

Partirei para tal do $\S 69$ do Tratado da Reforma do Entendimento. Neste parágrafo Espinosa nos diz que:

"Quanto ao que constitui a forma do verdadeiro, é certo que o pensamento verdadeiro não se distingue somente do falso por uma denominação extrínseca, mas sobretudo por uma denominação intrínseca".

O emprego do advérbio "sobretudo" nesta passagem marca nitidamente a primazia da denominação intrínseca em relação à extrínseca, mas a afirmação da subordinação da última à primeira não é equivalente à afirmação de sua exclusão em proveito dela. No entanto, os exemplos dados em seguida por Espinosa parecem caminhar no sentido de uma verdadeira exclusão. Com efeito, continua ele,

"se um construtor concebe, segundo certa ordem, uma construção qualquer, ainda que esta construção nunca tenha existido, nem venha jamais a existir, o seu pensamento nem por isso é menos verdadeiro, e o pensamento permanece o mesmo, quer a construção exista, quer não; se, ao contrário, por exemplo, alguém diz que Pedro existe sem que, entretanto, saiba que Pedro existe, esse pensamento a seu respeito é falso, ou, se se prefere, esse penșamento não é verdadeiro ainda que Pedro de fato exista. E esta proposição, 'Pedro existe', só é verdadeira para aquele que sabe com certeza que Pedro existe".

O segundo exemplo afirma claramente que o mero acordo entre uma afirmação e o estado de coisas ao qual ela reenvia não é uma condição suficiente para considerá-la como verdadeira, enquanto o primeiro exemplo parece ir mais longe e afirmar que ele tampouco é uma condição necessária da 
Gleizer, M.A., discurso (24), 1994: 129-145

verdade, pois o plano concebido pelo construtor é dito "verdadeiro" independentemente da existência de seu objeto, razão pela qual esse texto parece reforçar a interpretação coerentista.

No entanto, parece-me possível interpretar o primeiro exemplo, à luz do que Espinosa nos diz na Ética, como afirmando simplesmente que a verdade de um conceito construído ordenadamente não depende de seu acordo com algo que exista na duração, sem que isso signifique que ele não concorde com uma essência eterna contida em um atributo.

No escólio da ProposiçãoVIII do Livro I, Espinosa afirma que:

"Nós podemos ter idéias verdadeiras de modificações não existentes; ainda que elas não existam em ato fora do entendimento, suas essências não estão menos contidas em outra coisa pela qual podemos concebê-las".

Isto não significa que a idéia verdadeira de uma essência seja a idéia de um ente simplesmente possível. O necessitarismo de Espinosa exclui toda interpretação ontológica das categorias modais de "possibilidade" e de "contingência". Estes predicados reenviam simplesmente a uma falta de conhecimento em nós, à nossa ignorância, não possuindo nenhum correlato no ser.

A exclusão da interpretação ontológica destas categorias modais leva Espinosa a sustentar que as essências das coisas singulares não são simples possibilidades lógicas, mas verdadeiras realidades tendo uma existência atual. Por exemplo, diz ele no escólio da Proposição XXIX do Livro V:

"As coisas são concebidas por nós como atuais de duas maneiras: ou enquanto concebemos que elas existem com relação a um tempo e a um lugar determinados, ou enquanto concebemos que elas estão contidas em Deus e que resultam da necessidade da natureza divina. Ora, as que são concebidas como verdadeiras ou reais desta segunda maneira, concebemo-las do ponto de vista da eternidade..." 
Para Espinosa, portanto, o contraste entre existência eterna e existência temporal não é um contraste entre existência possível e existência atual, mas entre dois tipos diferentes de existência atual. As essências das coisas singulares, sendo seres atuais, têm uma existência eterna que não se confunde com a existência na duração dos modos de que são essências. Assim, parece-me legítimo afirmar que não há para Espinosa idéia verdadeira que não concorde com um objeto tendo uma existência atual, seja esta existência temporal ou eterna. Toda idéia verdadeira tem um alcance existencial. Esta leitura permite manter a presença constante da dimensão extrínseca da verdade, afirmada no $\$ 42$ do próprio Tratado da Reforma do Entendimento ("A idéia deve concordar inteiramente com sua essência formal"), numa formulação semelhante àquela do Axioma VI do Livro I.

Podemos assim voltar ao Tratado da Reforma do Entendimento. Entre as duas denominações da idéia verdadeira, é sobretudo a denominação intrínseca que constitui a forma do verdadeiro. É ela que permite considerar a idéia verdadeira como tendo mais realidade ou perfeição interna que uma idéia falsa, é ela que permite afirmar que há entre a idéia verdadeira e a falsa a mesma relação que entre o ser e o não ser (Espinosa 3, escólio da Proposição XLIII do Livro II), ou ainda que é preciso mais potência para afirmar que o que é verdadeiro é verdadeiro do que para afirmar que o que é falso é verdadeiro (idem, escólio da Proposição XLIX do Livro II). É nela que consiste este "algo de real" ( $(70)$ pelo qual as idéias verdadeiras distinguem-se das falsas, este "algo de real", como veremos, consistindo na posse efetiva de um saber referente ao que afirmamos. Isto liga indissoluvelmente o conceito de verdade àquele de saber, e o conceito de falsidade àquele de ignorância (não contudo à ignorância absoluta, mas àquela que consiste numa privação relativa de conhecimento, isto é, numa privação de conhecimento relativa ao que se afirma. Espinosa não confunde erro com ignorância).

Se a verdade da idéia se reduzisse a sua dimensão extrínseca, parece que nós seríamos forçados a adotar a interpretação realista da definição nominal da verdade. Segundo esta interpretação, uma idéia é verdadeira porque ela é conforme ao seu objeto. Neste caso, é o objeto que torna a idéia verdadeira, é a presença de uma realidade exterior que é a norma da verdade da idéia. Ora, isto é totalmente contrário à tese espinosana segundo a qual 
"a verdade é norma de si mesma e do falso". Assim, esta tese não podendo ser fundada sobre a denominação extrínseca da idéia verdadeira e a definição da verdade a ela conectada, deverá fundar-se sobre a denominação intrínseca da idéia verdadeira. A adaequatio deverá fornecer um aspecto complementar à definição da verdade que funcione ao mesmo tempo como norma da verdade.

Se digo "aspecto complementar", é para sublinhar ainda uma vez que isto não significa que se deva excluir a definição nominal da verdade. Esta afirma simplesmente que a idéia verdadeira concorda com o seu objeto. Ela não determina em que consiste este acordo, nem tampouco qual é, dentre os termos da relação, aquele que torna a idéia verdadeira. A interpretação realista vai mais longe porque ela afirma que é o objeto que torna a idéia verdadeira. Pode-se no entanto manter esta definição excluindo sua interpretação realista. Neste caso, deve-se dizer que a idéia verdadeira, sendo intrinsecamente verdadeira (adequada), deve concordar com o seu objeto, quer dizer, deve ter também a denominação extrínseca. Só a exclusão da interpretação realista permite compatibilizar os dois aspectos da idéia verdadeira ${ }^{(3)}$.

Estas considerações permitem avançar na compreensão do Axioma VI do Livro I e do emprego do termo "debet" na sua formulação. Este axioma é enunciado da seguinte maneira: "A idéia verdadeira deve convir ao seu ideato”. Segundo o que foi dito acima, ele deve ser interpretado como equivalendo à seguinte formula:

1) Se uma idéia é verdadeira (intrinsecamente verdadeira, adequada), então ela concorda necessariamente com o seu objeto.

E não como equivalendo à esta outra:

2) Se uma idéia concorda com o seu objeto, então ela é necessariamente verdadeira.

O termo "debet" exprime o fato para a denominação extrínseca de ser uma conseqüência necessária da potência intrínseca do pensamento verdadeiro, o que significa que na relação de complementaridade há subordinação da convenientia à adaequatio.

Esta leitura que exclui o caráter realista da definição nominal pode ser reforçada e clarificada pela análise do segundo exemplo dado por Espinosa no $\S 69$ do Tratado da Reforma do Entendimento, aquele referente à afirma- 
ção existencial de Pedro. Segundo esta passagem, o simples encontro fortuito entre um estado de coisas e a afirmação que o representa não basta (não é uma condição suficiente) para que esta afirmação possa ser qualificada de verdadeira. A mera e casual existência do estado de coisas afirmado não torna a idéia verdadeira. Por outro lado, esta mesma afirmação feita com conhecimento de causa, isto é, ligada a uma idéia adequada que traz em si a totalidade das causas ou razões do que se afirma, receberá legitimamente este predicado. Só uma afirmação conectada com o sistema de razões que a justifica pode ser verdadeira. Como afirma Espinosa:

"Se alguém diz que Pedro existe sem que, entretanto, saiba que Pedro existe, esse pensamento a seu respeito é falso, ou, se se prefere, esse pensamento não é verdadeiro ainda que Pedro de fato exista. E esta proposição, 'Pedro existe', só é verdadeira para aquele que sabe com certeza que Pedro existe".

É preciso fazer uma observação a propósito do sentido da expressão “e esta proposição, 'Pedro existe', só é verdadeira para aquele que sabe com certeza que Pedro existe”. Espinosa não afirma que a proposição só é verdadeira para aquele que sabe com certeza que ela é verdadeira, já que isto consistiria em fazer depender a verdade de uma idéia do reconhecimento de sua verdade, isto é, em fazer depender a idéia verdadeira da idéia da idéia verdadeira, o que seria absurdo. É necessário distinguir a expressão "uma afirmação só é verdadeira se possuímos um saber certo referente ao objeto afirmado", da expressão "uma afirmação só é verdadeira se possuímos um saber certo quanto a sua verdade [a verdade da afirmação]".

Esta segunda expressão, como disse, é absurda por fazer depender a verdade do reconhecimento da verdade. A primeira, por sua vez, indica que a verdade de uma afirmação, estando intrinsecamente ligada à posse de um saber certo concernente ao objeto, isto é, a uma idéia adequada do objeto, aquilo que torna a idéia verdadeira coincide com aquilo que torna sua verdade diretamente reconhecível, e é esta coincidência que é expressa pelo verum index sui. 
Assim, para Espinosa, não há proposição verdadeira sobre algo que não seja a expressão de um saber certo sobre este algo. No conhecimento verdadeiro há uma relação indissociável entre o que é afirmado e as razões pelas quais isto é afirmado, o que leva Espinosa a afirmar no escólio da Proposição XLIII do Livro II que:

"Ter uma idéia verdadeira, com efeito, não significa senão conhecer uma coisa perfeitamente ou o melhor possível (perfecte sive optime)".

"Perfeitamente ou o melhor possível" designa a forma pela qual a coisa é conhecida, o processo de engendramento do conhecimento. E este processo, não sendo uma operação que permaneça exterior à verdade da afirmação a qual ele conduz, mas sendo parte integrante da significação mesma da verdade desta, não é possível que uma afirmação seja verdadeira se ela estiver desprovida desta forma, ou seja, se ela não for um conhecimento perfeito de seu objeto. Espinosa sustenta assim algo como uma concepção epistêmica da verdade.

$\mathrm{O}$ famoso exemplo da quarta proporcional ilustra bem esta indissociabilidade entre o que se afirma e as razões que provam o que se afirma na idéia verdadeira. Com efeito, o mesmo resultado (uma mesma afirmação) pode ser atingido mediante procedimentos - modos de percepção ou ainda gêneros de conhecimento - que divergem qualitativamente, e esta divergência quanto à maneira de alcançar o resultado permite incluir alguns e excluir outros da esfera da verdade.

A simples aplicação cega de uma regra (regra de três) que nós aprendemos por ouvir dizer, mas cuja razão nos escapa (primeiro modo de percepção), ou ainda que foi encontrada a partir de experiências particulares não guiadas pela razão e generalizada em seguida de uma maneira abusiva (segundo modo de percepção), não permitindo que nós compreendamos a necessidade do resultado, conduz a afirmações gratuitas e incertas que não podem ser qualificadas de verdadeiras. Mesmo se a aplicação da regra nos conduz ao resultado "correto", a mera impossibilidade de dar conta do caminho que aí conduz, a incapacidade de explicar como e por que algo é 
necessariamente o caso, a exclui da verdade. Estes modos de percepção, que fazem parte do primeiro gênero de conhecimento na Ética, são inadequados e conseqüentemente não-verdadeiros.

Por sua vez, a aplicação da regra compreendida a partir das propriedades comuns dos números proporcionais (terceiro modo de percepção, segundo gênero de conhecimento) ou ainda a inferência direta da quarta proporcional a partir da intuição da relação entre o primeiro e o segundo números (quarto modo de percepção, terceiro gênero de conhecimento), sendo procedimentos que podem dar conta do processo que os conduz ao resultado, e por aí mesmo da necessidade deste, estão na verdade.

$A$ indissociabilidade entre a operação racional que funda e justifica uma determinada afirmação e a verdade desta afirmação, a imanência do procedimento demonstrativo à verdade, significa que a rejeição da interpretação realista da definição nominal da verdade é acompanhada em Espinosa da exclusão consecutiva daquele princípio que Dummet chama de "princípio do conhecimento", segundo o qual: "Um enunciado pode ser verdadeiro mesmo se nós não podemos conhecer aquilo que o torna verdadeiro". Tratase de um princípio característico do realismo e que estabelece uma nítida separação entre o fato de uma proposição ser verdadeira e as razões que permitem considerá-la como tal.

Deve-se sublinhar no entanto que a exclusão da interpretação realista da definição nominal da verdade e do princípio do conhecimento não fazem de Espinosa um idealista. Segundo ele, jamais o ser das coisas se reduz ao fato para elas de serem pensadas. Mesmo se tudo o que existe é necessariamente objeto de uma idéia em Deus, não é isso que constitui sua realidade, já que Espinosa exclui categoricamente a hipótese de um entendimento criador. Sua posição poderia ser caracterizada como aquela de um realista metafísico que, em virtude de seu construtivismo, rejeita o realismo epistemológico. Isto significa que apesar de aceitar a existência independente de uma realidade exterior ao pensamento, ele nega a função desta realidade tanto na produção das idéias quanto na determinação de seu valor de verdade.

Por fim, gostaria de aproximar o que Espinosa afirma no $§ 69$ do Tratado da Reforma do Entendimento do que Descartes sustenta nas suas $\mathrm{Me}$ - 
ditações Metafísicas. Esta aproximação permitirá apreender melhor a originalidade do pensamento de Espinosa.

Nós encontramos nas Meditações duas passagens que ilustram a posição de Descartes a propósito do "princípio do conhecimento". A primeira encontra-se no início da Terceira Meditação, onde Descartes nos fala das coisas que ele considerara inicialmente como muito certas e que reconheceu em seguida serem duvidosas:

"Mas havia ainda outra coisa que eu afirmava, e que, devido ao hábito que tinha de acreditar nela, pensava perceber mui claramente, embora na verdade não a percebesse de modo algum, a saber, que havia coisas fora de mim donde procediam essas idéias e às quais elas eram inteiramente semelhantes. E era nisso que eu me enganava; ou, se eu julgava talvez segundo a verdade, não havia nenhum conhecimento que eu tivesse que fosse causa da verdade de meu julgamento [si verum judicabam, id non ex vi meae percepcionis contingebat]".

Nesta passagem Descartes admite que se aquilo que ele julgava fosse efetivamente o caso, seu juízo seria verdadeiro, malgrado a ausência de uma percepção clara e distinta do que ele afirmava. Seu juízo seria verdadeiro não pela virtude (ex vi) da sua percepção, mas, poderíamos dizer, graças a um encontro casual com a realidade. Sua hesitação ("Era nisso que eu me enganava; ou, se eu julgava talvez segundo a verdade...") não recai sobre a legitimidade de caracterizar um juízo deste tipo como verdadeiro, mas sobre a possibilidade de reconhecer ou de determinar esta verdade. O juízo seria, absolutamente falando, verdadeiro, mas a ausência de uma percepção clara e distinta o impediria de reconhecer esta verdade.

Espinosa, por sua vez, não hesita em considerar um tal juízo, em função da ausência mesma de uma percepção adequada do que é afirmado, como estando fora da esfera da verdade. E isto mesmo se o que ele afirma for o caso. Para ele, um juízo cuja verdade não depende da virtude, isto é, da potência explicativa do pensamento, não merece ser qualificado de "verda- 
deiro". Sua única hesitação recai sobre a maneira de designá-lo, hesitando entre o predicado "falso" e o predicado "não-verdadeiro" ("Seu pensamento... é falso ou, se se prefere, não é verdadeiro, ainda que Pedro exista efetivamente").

Em.Descartes, a ausência de clareza e distinção, quer dizer do critério de verdade, impede o reconhecimento da verdade, mas o juízo permanece, malgrado isso, verdadeiro. Há dissociação entre o que identifica e o que torna um juízo verdadeiro. Em Espinosa, a ausência de adequação, isto é, da propriedade intrínseca da idéia verdadeira, impede que o juízo possa ser, no sentido plenamente espinosano, verdadeiro, e a fortiori que possa haver um reconhecimento qualquer de sua verdade.

A outra passagem de Descartes encontra-se na Quarta Meditação, no contexto de uma discussão sobre o bom uso do livre-arbítrio:

"Ora, se me abstenho de formular meu juízo sobre uma coisa, quando não a concebo com suficiente clareza e distinção, é evidente que o utilizo muito bem e que não sou enganado; mas, se me determino a negá-la ou a assegurá-la, então não me sirvo como devo de meu livre-arbítrio; se asseguro o que não é verdadeiro, é evidente que me engano, e até mesmo, ainda que julgue segundo a verdade, isto não ocorre senão por acaso e eu não deixo de falhar e de utilizar mal o meu livre-arbítrio".

Aqui Descartes afirma claramente que um juízo que concordasse por acaso com a realidade não deixaria de ser um juízo verdadeiro. Se ele o aproxima de um juízo falso, ele não chega a qualificá-lo de falso como faz Espinosa. Esta aproximação visa chamar atenção sobre o fato de que uma verdade encontrada por acaso reenvia, assim como um juízo falso, a um mau uso do livre-arbítrio. Mas uma verdade encontrada por acaso não deixa de ser uma verdade, mesmo se ela encontra na sua raiz o mesmo mau uso do livre-arbítrio que engendra a falsidade. Vemos assim como em Descartes, contrariamente ao que se passa com Espinosa, é a presença do objeto exterior que tem a função de tornar o juízo verdadeiro, e como a ausência da 
evidência não o torna falso, mas somente duvidoso. Isto mostra como a interpretação realista da definição nominal da verdade é acompanhada do "princípio de conhecimento", e como a exclusão de um acarreta aquela do outro:

Assim, é a exclusão da interpretação realista da definição nominal da verdade que permite a Espinosa dissolver a tensão assinalada por Alquié, e tornar compatíveis as duas propriedades da verdade. Porém, para compreender não apenas a compatibilidade destas propriedades, mas a necessidade de sua ligação, explicitando a razão pela qual a correspondência é uma conseqüência necessária da adequação, é preciso examinar a doutrina do paralelismo, isto é, a função do absoluto na fundamentação da complementaridade entre os dois aspectos da verdade, o que ultrapassa entretanto os objetivos e limites da presente exposição.

Abstract: This article investigates some features of Spinoza's philosophy which provides the ground to set up a relationship of complementarity between the notions of adequacy and correspondence as they appear in his conception of truth. This investigation aims to make an opposition between this relationship of complementarity to that between the notions of evidence and truth presented in the Cartesian conception.

Key-words: definition of truth - criterion of truth - correspondence - adequacy - coherence 


\section{Notas}

(1) Deve-se observar que Landim parece distinguir aqui entre o que constitui propriamente a verdade (a correspondência) e o que nos permite reconhecê-la (a coerência), visto que ele afirma que a coerência é o que faz com que a verdade se imponha ao homem como correspondência. Assim, mais que a coexistência de duas teorias da verdade, trata-se na realidade de uma distinção entre a definição da verdade e o critério da verdade, cabendo uma exclusividade definicional à correspondência e uma função meramente recognitiva à coerência-adequação.

(2) A numeração dos parágrafos utilizada aqui é a de Bruder, retomada na edição de Koyré.

(3) Deve-se notar que Espinosa não apresenta na Ética, nem aliás no Tratado da Reforma do Entendimento, uma definição em forma e explícita da verdade. $\mathrm{Na}$ Ética a tradicional definição nominal da verdade não é apresentada por ele sob forma de definição, mas sob forma de axioma (Axioma VI do Livro I). Não se deve pensar que a substituição do enunciado definicional pelo enunciado axiomático seja gratuita. Com efeito, as definições recaem sobre as essências das coisas e suas afeç̧ões, enquanto os axiomas concernem às relações entre as coisas. Assim, a formulação axiomática da definição nominal visa indicar que esta recai apenas sobre a relação extrínseca da idéia verdadeira ao seu objeto, e que ela não nos diz em que consiste a idéia verdadeira tomada nela mesma, abstração feita desta relação. A substituição do enunciado definicional pelo axiomático não significa entretanto a supressão da correspondência como um elemento (embora não o único) constitutivo da concepção espinosana da verdade. Por esta razão, $e$ para facilitar a exposição do tema, tomei a liberdade de manter a designação tradicional de definição nominal para referir-me a este elemento. 


\section{Referências Bibliográficas}

1. ALQUIÉ, F. Le Rationalisme de Spinoza. Col. Épiméthée. Paris, PUF, 1981.

2. DESCARTES, R. Oeuvres Philosophiques. Vol. 2. Ed. F. Alquié Paris, Garnier, 1973.

3. ESPINOSA, B. Éthique. Ed. bilíngüe. Trad. e notas de Ch. Appuhn. Paris, Vrin, 1983.

4. _ Traité de la Réforme de l'Entendement. Ed. bilíngüe. Trad. e notas de A. Koyré. Paris, Vrin, 1984.

5. LANDIM, R. "La Notion de Vérité dans l'Éthique de Spinoza". In: Groupe de Recherches Spinozistes; Travaux et Documents, $\mathrm{n}^{2} 2$. Paris, PUF, 1989. 